\title{
Radiation Shielding Property of Concrete Using the Rapidly Cooled Steel Slag from Oxidizing Process in the Converter Furnace as Fine Aggregate
}

\author{
Kim, Jin-Man ${ }^{1}$ Cho, Sung-Hyun ${ }^{2} \quad$ Kwak, Eun-Gu ${ }^{3 *}$ \\ Department of Architectural Engineering, Kongju National University, Cheon-an, ChungNam, 330-717, Korea ${ }^{1}$ \\ Hanil Cement technical center, DaeJeon, 306020, Korea ${ }^{2}$ \\ Environment-Friendly Concrete center, Kongju National University, Cheon-an, ChungNam, 330-717, Korea ${ }^{3}$
}

\begin{abstract}
Each year, about four million tons of steel slag, a by-product produced during the manufacture of steel by refining pig iron in the converter furnace, is generated. It is difficult to recycle this steel slag as aggregate for concrete because the reaction with water and free- $\mathrm{CaO}$ in steel slag results in a volume expansion that leads to cracking. However, the steel slag used in this study is atomized using an air-jet method, which rapidly changes the melting substance at high temperature into a solid at a room temperature and prevents free- $\mathrm{CaO}$ from being generated in steel slag. This rapidly-cooled steel slag has a spherical shape and is even heavier than natural aggregate, making it suitable for the aggregate of radiation shielding concrete. This study deals with the radiation shielding property of concrete that uses the rapidly-cooled steel slag from the oxidizing process in the converter furnace as fine aggregate. It was shown that the radiation shielding performance of concrete mixed with rapidly-cooled steel slag is even more superior than that of ordinary concrete.
\end{abstract}

Keywords : rapid-cooled steel slag, radiation shielding concrete, analysis of radiation shielding

\section{Introduction}

The construction plan for the Shin-wooljin nuclear power plant and a number of contracts of nuclear power plant construction planned have recently been in issue. In general, of the radiation shielding technologies for structures, heavy weight concrete that contains metal aggregate, including magnetite and hematite with high content of iron $(\mathrm{Fe})$, and that makes the concrete heavier in weight is typically used, or the walls are built thicker with OPC. However, it is difficult to

Received : November 30, 2011

Revision received : June 27, 2012

Accepted : July 15, 2012

* Corresponding author : Kwak, Eun-gu

[Tel: 82-41-566-8651, E-mail: keg7707@kongju.ac.kr]

(c)2012 The Korea Institute of Building Construction, All rights reserved. smoothly supply the metal aggregate such as magnetite or hematite, bringing about an increase in construction cost, and it presents a high risk of cracks on concrete caused by heat of hydration due to the increased wall thickness[1,2]

Korea is the world' $\mathrm{s} 5^{\text {th }}$ largest producer of iron, and the production quantity is increasing annually, which means that the quantity of by-products is also increasing. By-products made in the process of iron production can be broadly classified into blast furnace slag and steel slag. Blast furnace slag is widely used as raw material for cement, concrete aggregate and recycled aggregate for road, while steel slag cannot be widely used because of its volume expansion and subsequent collapse by free lime(CaO), which means that there are limitations in terms of its use as construction material[3,4,5]. 
Recently a technique for manufacturing stable aggregate for concrete was developed that uses rapid cooling of the fused steel slag to prevent free $\mathrm{CaO}$ from being generated. Studies have been actively conducted to find more appropriate usages of the aggregate[6,7]. When the slag is rapidly cooled, the content of free $\mathrm{CaO}$ that could cause a volume expansion and subsequent collapse is $0.15 \%$, and the rapidly cooled steel slag was reported to be stable in the situation of volume expansion and collapse[8]. The particle shape of rapidly cooled steel slag aggregate has high roundness or sphericity, which leads to high solid volume and unit volume weight. The steel slag is characterized to have high density due to there being about $40 \%$ of iron $(\mathrm{FeO})$ in chemical property. Studies have been actively performed on the physical characteristics of rapidly cooled steel slag aggregate to use the aggregate for high density concrete and for polymer concrete with the utilization of high solid volume. However, there have been few studies done on the characteristics of its high density. It is believed the rapidly cooled steel slag can be used in place of the existing metal aggregate such as magnetite or hematite with high density[9].

Accordingly, the radiation shielding characteristics of the concrete with rapidly cooled steel slag were tested to determine whether or not the rapidly cooled steel slag could be utilized as aggregate for radiation shielding concrete. To do this, the replacement ratio of the rapidly cooled steel slag was set differently to manufacture the radiation shielding concrete specimen. Specimens were then tested to determine their radiation shielding ability. Radiation shielding by thickness was evaluated using the Monte Carlo method based on the measurement result of radiation shielding to conduct a quantitative analysis of the reduction in thickness of a shielding body when using the rapidly-cooled steel slag instead of natural aggregate.

\subsection{Research method and scope}

This study aims to determine the possibility of using, as aggregate for radiation shielding concrete, the steel slag generated by rapidly cooling the converter slag obtained in the process of iron production using an air-jet method. For the experiment and analysis, the previous studies related to radiation shielding analysis and the shielding analysis using source term were reviewed. Based on the review, concrete specimens were manufactured using the rapidly-cooled steel slag as aggregate. A gamma ray spectrometer was used to analyze the radiation shielding ability.

\section{Literature review}

\subsection{Principles of shielding analysis}

The basic principle of radiation shielding analysis is to obtain the solution of the transport equation. Known as the Boltzmann transport equation, the transport equation can be largely divided into two approaches.

One is the deterministic approach, which expresses the radiation field using the equation that shows energy and transport direction, and distribution of number density at a given point. Distribution of number density was determined by a mathematical transport equation.

The other is the probability approach, a simulation of particle trajectory according to reaction probability, using probability distribution function. The probability approach is called the Monte Carlo method, which is a class of computational algorithms that can calculate the average value of repeated random behaviors of particles as a deterministic value.

The Monte Carlo method has been used widely 
not only because the cross-section of continuous has recently been used to resolve the fundamental problem with the solution, but also because it provides an accurate 3D simulation of the transport process in the given structure. The Monte Carlo method takes considerable time to simulate the actual behaviors of particles as they are. With the rapid advancement of computing technologies in recent years, the problems caused by computer performance have been gradually resolved. Therefore, the system given in terms of radiation shielding analysis is considerably complex, and it is better to employ the Monte Carlo method that performs a statistical analysis compared with numerical approximation. The Monte Carlo method is based on statistic characteristics, and its drawback is that a numerically analyzed solution cannot be obtained. In addition, there is some statistical uncertainty in the result obtained though the Monte Carlo method. In other words, the deterministic approach gives an accurate true value of quantity through simplification and approximation of a given problem, while the Monte Carlo method gives all the approximate solutions through an accurate simulation of a given problem[10].

There are diverse Monte Carlo radiation transport codes, including MCNP, MORSE, EGS, and ETRAN. Of these, MCNP code has a long history, having been developed since the 1970s with massive investments of manpower and time, including more than 500 researchers. The MCNP is the most widely used Monte Carlo radiation transport code in the world. The reliability of MCNP was proven for its use in diverse radiation-related fields.

The MCNP code was first introduced in 1983, and MCNP3 was distributed throughout the world. Since then it has been improved to have electrical transport function in MCNP4A(1990), and continued to be developed into MCNP4B(1997) and MCNP4C(2000). In addition, the recent release of MCNPX 2.4 has improved to expand the radiation energy range up to $150 \mathrm{MeV}$ from the previous model MCNP4C. It is designed to transport a total of 34 particles including proton, helium nucleus, and other elementary particles. The radiation analysis was extended to apply to the following fields:

- Research of radioactive isotope production using an particle accelerator, including transmutation of radioactive waste

- Studies of cosmic-ray radiation shielding for high-altitude airliners and space shuttles

- Neutron and proton therapy

- Accelerator-based imaging using neutron and proton

- Neutrino experiment

- Radiation protection and shielding

- Radiation shielding design for particle accelerator

- Safety analysis of nuclear criticality, etc.

\subsection{Radiation shielding analysis by source item}

The radiation shielding analysis is divided into three or four steps. First, the source term is analyzed. Second, the distribution and intensity of radiation, which is the most fundamental element in the radiation shielding, is evaluated at a point after radiation was put.

The most basic question in the design and analysis of radiation shielding is whether or not the wall is sufficiently thick to protect people or living creatures from gamma rays or neutrons. These two rays penetrate more than other types of radioactive rays, and it is difficult to lessen their intensity. In a nuclear power plant, a variety of gamma rays are generally emitted. Gamma rays 
Table 1. Mix plan

\begin{tabular}{|c|c|c|c|c|c|c|c|c|c|c|c|c|c|c|c|}
\hline \multirow{3}{*}{$\begin{array}{l}\text { W/C } \\
(\%)\end{array}$} & \multirow{3}{*}{ 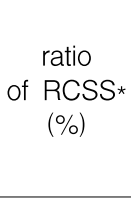 } & \multirow{3}{*}{$\begin{array}{l}\text { Target } \\
\text { slump } \\
(\mathrm{cm})\end{array}$} & \multirow{3}{*}{$\begin{array}{c}\text { Fine } \\
\text { Agg. } \\
\text { ration } \\
(\%)\end{array}$} & \multirow{3}{*}{$\begin{array}{c}\text { Unit } \\
\text { water } \\
\left(\mathrm{kg} / \mathrm{m}^{3}\right)\end{array}$} & \multicolumn{5}{|c|}{ Unit volume $\left(\mathrm{I} / \mathrm{m}^{3}\right)$} & \multicolumn{5}{|c|}{ Unit weight $\left(\mathrm{kg} / \mathrm{m}^{3}\right)$} & \multirow{3}{*}{ Test items } \\
\hline & & & & & \multirow{2}{*}{$\underset{t}{\text { Cemen }}$} & \multicolumn{2}{|c|}{ Fine agg. } & \multicolumn{2}{|c|}{ Coarse agg. } & \multirow{2}{*}{$\begin{array}{c}\text { Cemen } \\
t\end{array}$} & \multicolumn{2}{|c|}{ Fine agg. } & \multicolumn{2}{|c|}{ Coarse agg. } & \\
\hline & & & & & & RCSS & $\begin{array}{l}\text { River } \\
\text { sand }\end{array}$ & RCSS & $\begin{array}{l}\text { Crush } \\
\text { agg. }\end{array}$ & & RCSS & $\begin{array}{l}\text { River } \\
\text { sand }\end{array}$ & RCSS & $\begin{array}{c}\text { Crushed } \\
\text { agg. }\end{array}$ & \\
\hline \multirow{6}{*}{35} & 0 & \multirow{6}{*}{$18 \pm 2.5$} & \multirow{6}{*}{46} & \multirow{6}{*}{175} & 159 & 288 & 0 & 0 & 338 & 500 & 743 & 0 & 0 & 872 & \multirow{6}{*}{$\begin{array}{c}\text { - Radiation } \\
\text { shielding } \\
\cdot \text { Atom ano } \\
\text { density }\end{array}$} \\
\hline & 25 & & & & 159 & 216 & 72 & 0 & 338 & 500 & 557 & 257 & 0 & 872 & \\
\hline & 50 & & & & 159 & 144 & 144 & 0 & 338 & 500 & 371 & 514 & 0 & 872 & \\
\hline & 75 & & & & 159 & 72 & 216 & 0 & 338 & 500 & 186 & 771 & 0 & 872 & \\
\hline & 100 & & & & 159 & 0 & 288 & 0 & 338 & 500 & 0 & 1028 & 0 & 875 & \\
\hline & All-100** & & & & 159 & 0 & 288 & 338 & 0 & 500 & 0 & 1028 & 1166 & 0 & \\
\hline
\end{tabular}

* RCSS : rapid-cooled steel slag

** All-100 : All aggregate uses rapid-cooled steel slag.

strong enough to penetrate the shielding body of the nuclear reactor are radiation generated through reaction with neutrons around the pressure vessel.

o Fission gamma rays

o Fission-product-decay gamma ray

o Capture gamma ray

o Inelastic-scattering gamma ray

o Reaction-product gamma ray

o Activation-product gamma ray

o Annihilation radiation

o Bremsstrahlung

In addition, the neutrons generated in the process of operating a nuclear power plant are created in the course of nuclear decay itself.

o Fission neutrons

o Activation neutrons

o Photo-neutrons

o Particle-reaction neutrons

To apply the shielding analysis and result, the energy of gamma ray equivalent to total energy was selected, and the neutron was classified into thermal neutron and fast neutron to analyze radiation shielding by dividing into sections depending on energy level.

\section{Experiment plan}

\subsection{Concrete mixture of specimens for shielding performance test}

Table 1 indicates the concrete mixture for specimen manufacture and radiation shielding analysis. The concrete specimen was mixed to have a water to cement ratio of $35 \%$, unit volume of cement of $500 \mathrm{~kg} / \mathrm{m}^{3}$, and fine aggregate ratio of $46 \%$.

The replacement ratio of rapidly-cooled steel slag was set as $0 \%, 25 \%, 50 \%, 75 \%$, and $100 \%$ against river sand. In addition, a mixture with rapidly-cooled steel slag in place of fine and coarse aggregate was considered.

\subsection{Materials}

Ordinary Portland cement with a density of 3.15 $\mathrm{g} / \mathrm{cm}^{3}$ was used. The physical properties of OPC are indicated in Table 2. River sand and rapidly-cooled steel slag were used as fine aggregate, and $19 \mathrm{~mm}$ crushed gravel and rapidly-cooled steel slag was used as coarse aggregate. The physical properties of aggregate are indicated in Table 3. Polycarbonate super-plasticizer (brown liquid, specific gravity 1) was used. 
Table 2. The physical properties of cement

\begin{tabular}{|c|c|c|c|c|c|c|}
\hline \multirow{2}{*}{$\begin{array}{c}\text { Density } \\
\left(\mathrm{g} / \mathrm{cm}^{3}\right)\end{array}$} & \multirow{2}{*}{$\begin{array}{l}\text { Blaine } \\
\left(\mathrm{cm}^{2} / \mathrm{g}\right)\end{array}$} & \multicolumn{2}{|c|}{ Settint Time (h:m) } & \multicolumn{3}{|c|}{ Comp. strength(MPa) } \\
\hline & & intitial & End & 3 day & 7 day & 28 day \\
\hline 3.15 & 3,254 & $4: 50$ & 7:05 & 18.3 & 25.0 & 35.0 \\
\hline
\end{tabular}

Table 3. The physical properties of aggregate

\begin{tabular}{cccccccc}
\hline Type & $\begin{array}{c}\text { Max } \\
\text { size } \\
(\mathrm{mm})\end{array}$ & $\begin{array}{c}\text { Density } \\
\left(\mathrm{g} / \mathrm{cm}^{3}\right)\end{array}$ & $\begin{array}{c}\text { Absor } \\
\text { ption } \\
(\%)\end{array}$ & F.M. & $\begin{array}{c}\text { Unit weight } \\
(\mathrm{kg} / \mathrm{m} 3)\end{array}$ & $\begin{array}{c}\text { Solid } \\
\text { ratio } \\
(\%)\end{array}$ \\
\hline Fine RCSS & 5 & 3.57 & 0.42 & 3.10 & 2.263 & 63.75 \\
agg. River & 5 & 2.58 & 1.19 & 3.30 & 1.575 & 63.40 \\
Coarse & RCSS & 19 & 3.48 & 0.90 & 7.41 & 1,908 & 55.23 \\
agg. & Crush & 19 & 2.58 & 0.99 & 6.96 & 1,507 & 58.93 \\
\hline
\end{tabular}

\subsection{Test specimen for radiation shielding}

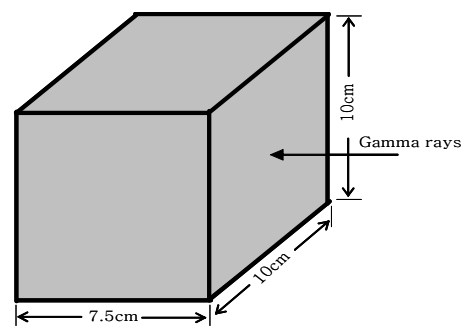

Figure 1. Size of Test specimen

As shown in Figure 1, the test specimen for radiation shielding was made to $7.5 \mathrm{~cm} \times 10 \mathrm{~cm} \times$ $10 \mathrm{~cm}$ in size and wet cured for 28 days at $20 \pm$ $3^{\circ} \mathrm{C}$. The radiation shielding was measured at 28 days of curing after the unit volume weight was measured using a test system for gamma ray illustrated in Figure 1. Cs $137-662 \mathrm{keV}$ gamma ray was used for the test.

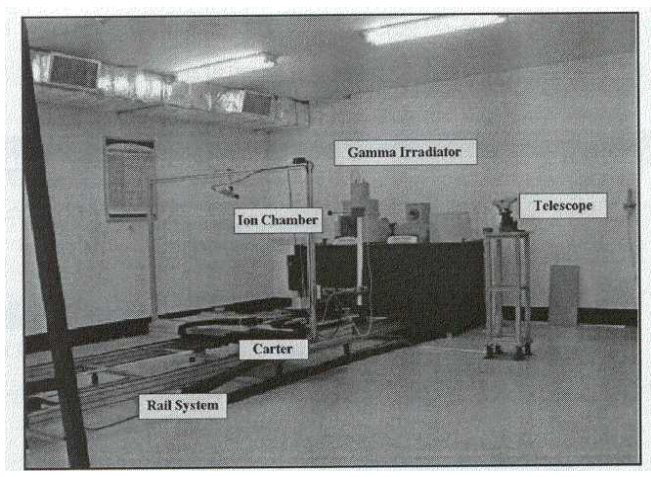

Figure 2. Test system of gamma

\subsection{A model for shielding calculation}

MCNPX 2.4 was used, which was designed to set the radiation transportable energy range at up to $150 \mathrm{MeV}$ applicable to the high-energy particle accelerator. In addition, the radioactive source was designed to be incident at the point $1 \mathrm{~m}$ away from the infinite slab, and the detector used in the test was made to be a volume of $30 \mathrm{~cm}$ sphere identical to the size of the measure.

In the test radiation beam was measured at 5, 10, 15, 20, 25 and $30 \mathrm{~cm}$ of shielding body, respectively not to mention $7.5 \mathrm{~cm}$ of wall thickness basically included in the test. The photon beam of $0.1,1$ and $10 \mathrm{MeV}$ and gamma ray of $662 \mathrm{keV}(\mathrm{Cs}$ 137) were selected for the source term to verify the test, and the pressurized water reactor (PWR) spectrum presented in the IAEA Technical Report 403 was used for the neutron source.

As the source term has the greatest impact on the shielding calculation, the accuracy of the description of the source term is an important factor that determines the reliability of code calculation. However, the object to be protected was not specifically selected in this study, and production evaluation of the neutron source term was done by computation for the protection to be employed for general use. IAEA Technical Report 403 "Compendium of neutron spectra and detector responses for radiation protection purposes" was referred to for the neutron source. The spectrum actually measured at the test room outside the reactor-pressured vessel now operated in the Czech Republic was entered directly on MCNPX to perform the computation[8]. IAEA Technical Report 403 presents in the tables and graphs typical neutron spectrums actually measured or computed at diverse facilities where neutron is detected, and it is expected that the technical report will be widely utilized when performing the shielding 
calculation for neutron flux, particularly in the fields in which information of the neutron source term is insufficient or unavailable. It provides a wide range of detailed neutron spectrums including typical PWR, BWR, particle accelerator for medical treatment, high-energy particle accelerator, cosmic-ray, nuclear fuel cycle facilities, various neutron sources, and Boron neutron capture therapy. The gamma energy used in this shielding analysis is the nuclide generally emitted from the nuclear power plant, which basically includes Cs 137 gamma ray that can be analyzed and evaluated in a laboratory. The shielding performance was evaluated according to energy level, and Co was selected as the gamma source that can be represented as a general photon beam because of its applicability from low-energy photon $(0.1 \mathrm{MeV})$ to high-energy photon(10MeV). In addition, it can be applied not only to a nuclear power plant but also to a general company.

\subsection{Geometric model and does conversion method}

The ultimate purpose of radiation shielding is to minimize radiation exposure of a human body. For this reason, to evaluate the shielding body containing the rapidly-cooled steel slag, a radiation shielding transport model was selected, and could be applicable to any of the shielding designs by assuming an infinite slab, which provides protection from a point source and the entire source. Infinite slab was assumed to minimize the uncertainty, since a geometric model is usually complex due to the high uncertainty caused by modeling. To concentrate the analysis on the shielding performance of the body, the parameters for the geometric model were used at the minimum.

In addition, by expressing the shielding performance in a percentile of radiation beam, the source can be applied regardless of beam and dose rate. Thus, when the effective beam was evaluated using ICRP74 or another method, it can be converted into dose rate by applying the shielding ratio.

\subsection{Verification of the evaluation method}

To verify the results of the analysis of shielding performance, the measurement values were obtained by measuring radiation transmissivity using a gamma spectrometer. In the test, the shielding concrete specimen made to the size of $7.5 \mathrm{~cm} \times 10 \mathrm{~cm} \times 10 \mathrm{~cm}$ and the test source of Cs 137-662kev was used. The shielding concrete used to make the specimen was analyzed in terms of element and density, and the analysis results are indicated in Table 4. Analysis values were obtained

Table 4. Atom analysis according concrete mix ratio

\begin{tabular}{|c|c|c|c|c|c|c|c|c|c|c|c|}
\hline $\begin{array}{c}\text { Rep. ratio of } \\
\text { RCSS } \\
(\%)\end{array}$ & \multicolumn{10}{|c|}{ Atom composition (wt/\%) } & \multirow{2}{*}{$\begin{array}{c}\begin{array}{c}\text { Density } \\
\left(\mathrm{g} / \mathrm{cm}^{3}\right)\end{array} \\
\begin{array}{c}\text { Density } \\
\left(\mathrm{g} / \mathrm{cm}^{3}\right)\end{array}\end{array}$} \\
\hline $\begin{array}{c}\text { Rep. ratio of } \\
\text { RCSS } \\
(\%)\end{array}$ & $\mathrm{Si}$ & $\mathrm{Al}$ & $\mathrm{Fe}$ & $\mathrm{Ca}$ & $\mathrm{Mg}$ & $\mathrm{Na}$ & K & $S$ & $\mathrm{H}$ & $\mathrm{O}$ & \\
\hline 0 & 26.40 & 5.57 & 3.46 & 11.18 & 1.33 & 1.08 & 1.28 & 0.24 & 0.81 & 48.65 & 2.32 \\
\hline 25 & 23.14 & 5.74 & 5.53 & 13.98 & 1.68 & 1.04 & 1.15 & 0.22 & 0.75 & 46.76 & 2.42 \\
\hline 50 & 20.10 & 5.91 & 7.47 & 16.59 & 2.01 & 0.99 & 1.03 & 0.20 & 0.69 & 45.00 & 2.50 \\
\hline 75 & 17.22 & 6.07 & 9.32 & 19.05 & 2.33 & 0.96 & 0.92 & 0.19 & 0.63 & 43.32 & 2.56 \\
\hline 100 & 14.54 & 6.22 & 11.04 & 21.33 & 2.63 & 0.91 & 0.82 & 0.18 & 0.57 & 41.76 & 2.67 \\
\hline All-100 & 6.82 & 4.60 & 16.39 & 29.90 & 4.58 & 0.01 & 0.16 & 0.17 & 0.40 & 36.97 & 3.00 \\
\hline
\end{tabular}


through an analysis using the MCNPX 2.4 code by assuming that the specimen was $7.5 \mathrm{~cm}$ thick and had an identical composition of elements and density to those shown in Table 4, and the source term of Cs 137-622kev was used. The validity was verified by comparing the measurement values with the analysis values.

\section{Analysis results and consideration}

\subsection{Verification of the shielding analysis}

Table 5 indicates the measurement values and the analysis values obtained through the aforementioned process. The values were determined through analysis to have been matched within up to $7.3 \%$. The difference is believed to be reasonable considering that the concrete specimen was heterogeneous and that a simple structure that could be generally used was considered, rather than reflecting the identical geometric structure to that in the measuring condition in consideration of the general use of the analysis values.

Table 5. Test and analysis according replacement ratio RCSS

\begin{tabular}{cccccccc}
\hline $\begin{array}{c}\text { Rep. ratio } \\
\text { of RCSS } \\
(\%)\end{array}$ & $\begin{array}{c}\text { Fine } \\
\text { aggreage }\end{array}$ & Coarse aggreage & \multicolumn{3}{c}{$\begin{array}{c}\text { Radiation } \\
\text { transmissivity }(\%)\end{array}$} \\
\hline $\begin{array}{c}\text { Rep. ratio } \\
\text { of RCSS } \\
(\%)\end{array}$ & River RCSS & $\begin{array}{c}\text { Crushed } \\
\text { agg. }\end{array}$ & RCSS & Test & Analysis & Gap \\
\hline 0 & 100 & 0 & 100 & 0 & 26.7 & 26.0 & 2.7 \\
25 & 75 & 25 & 100 & 0 & 25.7 & 24.7 & 4.0 \\
50 & 50 & 50 & 100 & 0 & 24.4 & 23.5 & 3.8 \\
75 & 25 & 75 & 100 & 0 & 23.6 & 22.8 & 3.5 \\
100 & 0 & 100 & 100 & 0 & 22.4 & 21.4 & 4.7 \\
All-100 & 0 & 100 & 0 & 100 & 19.2 & 17.9 & 7.3 \\
\hline * Test date is used specimen thickness $75 \mathrm{~mm}$ & & \\
Analysis date is a date of simulation & \multicolumn{3}{c}{}
\end{tabular}

Through this verification, it was proven that the source term and the geometric structure for computation was performed appropriately. The computation process was applied to all the energies to be analyzed in this study and the computation was performed.

\subsection{Evaluation and review of radiation shielding}

\subsubsection{Gamma ray of Cs137 - $662 \mathrm{keV}$}

Table 6 indicates the analysis results by radiation transmissivity and shielding thickness according to the replacement ratio of the rapidly-cooled steel slag. Figure 3 illustrates the analysis results of Cs137-662KeV by replacement ratio and radiation transmissibility in a semi log plot.

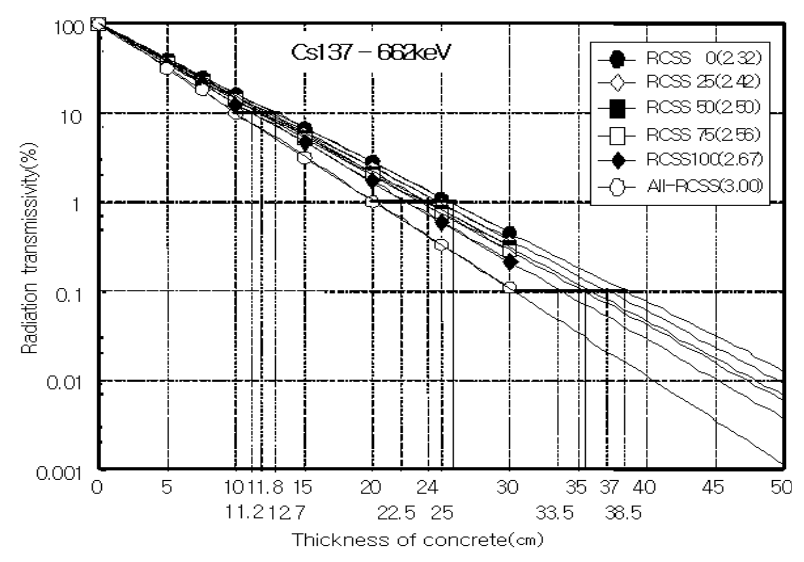

Figure 3 . Correlation on the gamma transmissivity according to specimen thickness $(662 \mathrm{keV})$

It was shown that the higher the replacement rate of rapidly-cooled steel slag as fine aggregate, the lower the gamma transmissivity. The intensity of Cs $137-622 \mathrm{keV}$ gamma ray was reduced by $1 / 10$, the thickness of $12.7 \mathrm{~cm}$ was needed when using river sand as aggregate while the thickness of $11.2 \mathrm{~cm}$ was needed when the aggregate was replaced $100 \%$ with the rapidly-cooled steel slag, from which it was proven to reduce by about $1.5 \mathrm{~cm}$ in thickness. In addition, when using fine and coarse aggregates together with rapidly-cooled steel slag, the thickness of $10 \mathrm{~cm}$ was needed, which was proven to reduce by about $2.7 \mathrm{~cm}$ in thickness compared with the wall using river sand and 
Table 6. Result of radiation Shielding

\begin{tabular}{|c|c|c|c|c|c|c|c|c|}
\hline & \multirow[b]{2}{*}{ Type } & \multirow{2}{*}{$\begin{array}{l}\text { Thickness } \\
(\mathrm{cm})\end{array}$} & \multicolumn{6}{|c|}{ Radiation transmissivity (\%) } \\
\hline & & & RCSS 0 & RCSS 25 & RCSS 50 & RCSS 75 & $\begin{array}{c}\text { RCSS } \\
100\end{array}$ & $\begin{array}{c}\text { All- } \\
\text { RCSS }\end{array}$ \\
\hline \multirow{40}{*}{$\begin{array}{c}\mathrm{G} \\
\mathrm{a} \\
\mathrm{m} \\
\mathrm{m} \\
\mathrm{a}\end{array}$} & \multirow{8}{*}{$\begin{array}{c}\text { CS137 } \\
(662 \mathrm{keV})\end{array}$} & 0 & 100.000 & 100.000 & 100.000 & 100.000 & 100.000 & 100.000 \\
\hline & & 5 & 40.671 & 39.350 & 38.110 & 37.425 & 35.778 & 31.619 \\
\hline & & 7.5 & 26.003 & 24.662 & 23.498 & 22.824 & 21.375 & 17.862 \\
\hline & & 10 & 16.619 & 15.550 & 14.603 & 14.067 & 12.867 & 10.138 \\
\hline & & 15 & 6.828 & 6.124 & 5.573 & 5.254 & 4.638 & 3.224 \\
\hline & & 20 & 2.801 & 2.428 & 2.146 & 1.995 & 1.673 & 1.025 \\
\hline & & 25 & 1.129 & 0.972 & 0.829 & 0.758 & 0.616 & 0.328 \\
\hline & & 30 & 0.449 & 0.371 & 0.309 & 0.290 & 0.214 & 0.109 \\
\hline & \multirow{8}{*}{$\begin{array}{c}\mathrm{CO} \\
(0.1 \mathrm{MeV})\end{array}$} & 0 & 100.000 & 100.000 & 100.000 & 100.000 & 100.000 & 100.000 \\
\hline & & 5 & 11.906 & 10.124 & 8.676 & 7.655 & 6.355 & 3.538 \\
\hline & & 7.5 & 4.119 & 3.216 & 2.558 & 2.129 & 1.604 & 0.683 \\
\hline & & 10 & 1.424 & 1.020 & 0.754 & 0.605 & 0.389 & 0.132 \\
\hline & & 15 & 0.166 & 0.109 & 0.064 & 0.047 & 0.028 & 0.004 \\
\hline & & 20 & 0.023 & 0.015 & 0.004 & 0.003 & 0.003 & 0.000 \\
\hline & & 25 & 0.003 & 0.003 & 0.002 & 0.001 & 0.000 & 0.000 \\
\hline & & 30 & 0.002 & 0.000 & 0.000 & 0.000 & 0.000 & 0.000 \\
\hline & \multirow{8}{*}{$\begin{array}{c}\mathrm{CO} \\
(1 \mathrm{MeV})\end{array}$} & 0 & 100.000 & 100.000 & 100.000 & 100.000 & 100.000 & 100.000 \\
\hline & & 5 & 47.694 & 46.340 & 45.133 & 44.481 & 42.886 & 38.885 \\
\hline & & 7.5 & 32.870 & 31.476 & 30.299 & 29.639 & 28.113 & 24.248 \\
\hline & & 10 & 22.710 & 21.458 & 20.381 & 19.774 & 18.426 & 15.208 \\
\hline & & 15 & 10.906 & 10.058 & 9.299 & 8.901 & 7.964 & 5.905 \\
\hline & & 20 & 5.206 & 4.676 & 4.230 & 3.942 & 3.445 & 2.332 \\
\hline & & 25 & 2.506 & 2.191 & 1.921 & 1.784 & 1.489 & 0.905 \\
\hline & & 30 & 1.215 & 1.014 & 0.870 & 0.792 & 0.660 & 0.346 \\
\hline & \multirow{8}{*}{$\begin{array}{c}\mathrm{CO} \\
(10 \mathrm{MeV})\end{array}$} & 0 & 100.000 & 100.000 & 100.000 & 100.000 & 100.000 & 100.000 \\
\hline & & 5 & 76.715 & 75.706 & 74.714 & 74.036 & 72.825 & 69.307 \\
\hline & & 7.5 & 67.131 & 65.721 & 64.413 & 63.596 & 62.003 & 57.617 \\
\hline & & 10 & 58.664 & 57.101 & 55.579 & 54.613 & 52.791 & 47.879 \\
\hline & & 15 & 44.949 & 43.073 & 41.359 & 40.332 & 38.371 & 32.997 \\
\hline & & 20 & 34.293 & 32.426 & 30.787 & 29.750 & 27.785 & 22.668 \\
\hline & & 25 & 26.239 & 24.504 & 22.867 & 21.887 & 20.118 & 15.793 \\
\hline & & 30 & 20.068 & 18.511 & 17.130 & 16.235 & 14.721 & 10.899 \\
\hline & \multirow{8}{*}{ Neutron } & 0 & 100.000 & 100.000 & 100.000 & 100.000 & 100.000 & 100.000 \\
\hline & & 5 & 15.405 & 15.502 & 15.700 & 16.352 & 16.266 & 17.298 \\
\hline & & 7.5 & 6.260 & 6.286 & 6.402 & 6.781 & 6.740 & 7.502 \\
\hline & & 10 & 2.646 & 2.676 & 2.724 & 2.938 & 2.907 & 3.357 \\
\hline & & 15 & 0.514 & 0.524 & 0.542 & 0.601 & 0.604 & 0.717 \\
\hline & & 20 & 0.122 & 0.119 & 0.123 & 0.150 & 0.145 & 0.179 \\
\hline & & 25 & 0.032 & 0.033 & 0.034 & 0.039 & 0.036 & 0.045 \\
\hline & & 30 & 0.013 & 0.013 & 0.012 & 0.012 & 0.014 & 0.015 \\
\hline
\end{tabular}


crushed gravel as aggregate. When the intensity of the gamma ray was reduced to $1 / 100$, the thickness of $26 \mathrm{~cm}$ was needed when using river sand as aggregate, while the thickness of $22.5 \mathrm{~cm}$ was needed when the aggregate was replaced $100 \%$ with rapidly-cooled steel slag, which proved that it could be reduced in thickness by about $4.5 \mathrm{~cm}$. When using fine and coarse aggregates together with rapidly-cooled steel slag, the thickness of $20 \mathrm{~cm}$ was needed, which was proven to have a reduction of about $6 \mathrm{~cm}$ in thickness compared with the wall using river sand and crushed gravel as aggregate. When the intensity of gamma ray was reduced to $1 / 1000$, the thickness of $38.5 \mathrm{~cm}$ was needed when using river sand as aggregate, while the thickness of $33.5 \mathrm{~cm}$ was needed when the aggregate was replaced $100 \%$ with rapidly-cooled steel slag, a reduction of about $5 \mathrm{~cm}$ in thickness. When using fine and coarse aggregates together with rapidly-cooled steel slag, the thickness of $30 \mathrm{~cm}$ was needed, which was a reduction of about $8.5 \mathrm{~cm}$ in thickness compared with the wall using river sand and crushed gravel as aggregate.

\subsubsection{Gamma ray of $\mathrm{Co}^{-}-0.1 \mathrm{MeV}$}

Figure 4 illustrates the results of an analysis of Co-0.1 MeV by replacement rate and gamma transmissivity in a semi log plot.

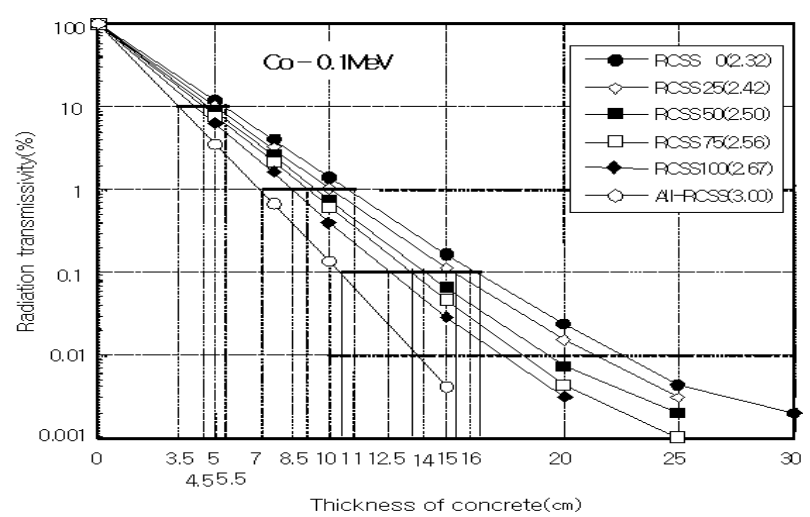

Figure 4. Correlation on the gamma transmissivity according to specimen thickness $(0.1 \mathrm{MeV})$
When the intensity of gamma ray of $\mathrm{Co}-0.1$ $\mathrm{MeV}$ was reduced by $1 / 10$, the thickness of $5.5 \mathrm{~cm}$ was needed when using river sand as aggregate while the thickness of $4 \mathrm{~cm}$ needed when the aggregate was replaced $100 \%$ with the rapidly-cooled steel slag, which was proven to reduce by about $1.5 \mathrm{~cm}$ in thickness. In addition, when using fine and coarse aggregates together with rapidly-cooled steel slag, the thickness of $3.5 \mathrm{~cm}$ was needed, which was proven to reduce by about $2 \mathrm{~cm}$ in thickness compared with the wall using river sand and crushed gravel as aggregate. When the intensity of gamma ray was reduced to $1 / 100$, the thickness of $11 \mathrm{~cm}$ was needed when using river sand as aggregate while the thickness of $8.5 \mathrm{~cm}$ was needed when the aggregate was replaced $100 \%$ with the rapidly-cooled steel slag, which was proven to reduce by about $2.5 \mathrm{~cm}$ in thickness compared with the wall using river sand crushed gravel as aggregate. When using fine and coarse aggregates together with rapidly-cooled steel slag, the thickness of $7 \mathrm{~cm}$ was needed, which was proven to reduce by about $4 \mathrm{~cm}$ in thickness compared with the wall using river sand and crushed gravel.

When the intensity of gamma ray was reduced to $1 / 1000$, the thickness of $16.5 \mathrm{~cm}$ was needed when using river sand as aggregate while the thickness of $13.5 \mathrm{~cm}$ was needed when the aggregate was replaced $100 \%$ with the rapidly-cooled steel slag, which was proven to reduce by about $3 \mathrm{~cm}$ in thickness compared with the wall using river sand crushed gravel as aggregate. When using fine and coarse aggregates together with rapidly-cooled steel slag, the thickness of $10.5 \mathrm{~cm}$ was needed, which was proven to reduce by about $6.5 \mathrm{~cm}$ in thickness compared with the wall using river sand and crushed gravel. 


\subsubsection{Gamma ray of $\mathrm{Co}^{-1}-1.0 \mathrm{Mev}$}

Figure 5 illustrates the results of an analysis of Co-1.0 MeV by replacement rate and gamma transmissivity in a semi log plot.

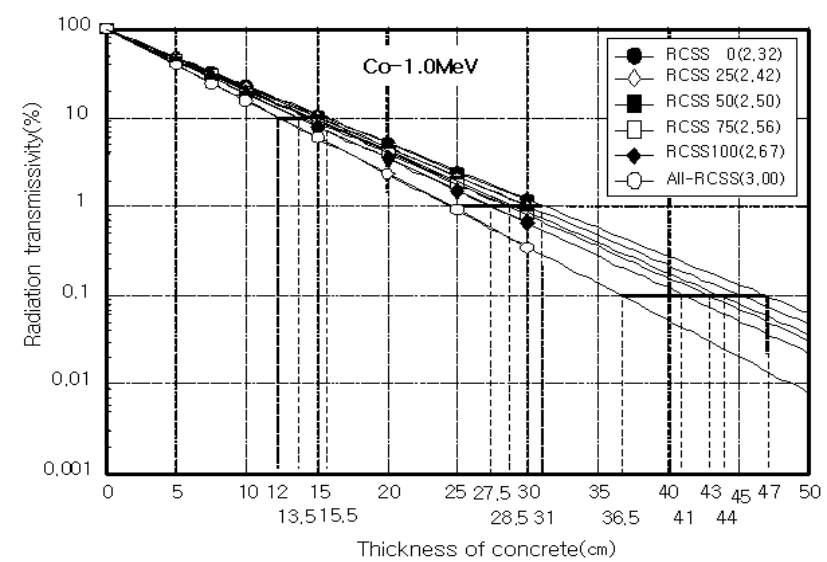

Figure 5. Correlation on the gamma transmissivity according to specimen thickness $(1.0 \mathrm{MeV})$

When the intensity of gamma ray of $\mathrm{Co}-1.0$ $\mathrm{MeV}$ was reduced by $1 / 10$, the thickness of $15.5 \mathrm{~cm}$ was needed when using river sand as aggregate while the thickness of $13.5 \mathrm{~cm}$ needed when the aggregate was replaced $100 \%$ with the rapidly-cooled steel slag, which was proven to reduce by about $2 \mathrm{~cm}$ in thickness. In addition, when using fine and coarse aggregates together with rapidly-cooled steel slag, the thickness of $12 \mathrm{~cm}$ was needed, which was proven to reduce by about $3.5 \mathrm{~cm}$ in thickness compared with the wall using river sand and crushed gravel as aggregate. When the intensity of gamma ray was reduced to $1 / 100$, the thickness of $31 \mathrm{~cm}$ was needed when using river sand as aggregate while the thickness of $27.5 \mathrm{~cm}$ was needed when the aggregate was replaced $100 \%$ with the rapidly-cooled steel slag, which was proven to reduce by about $3.5 \mathrm{~cm}$ in thickness compared with the wall using river sand crushed gravel as aggregate. When using fine and coarse aggregates together with rapidly-cooled steel slag, the thickness of $25 \mathrm{~cm}$ was needed, which was proven to reduce by about $6 \mathrm{~cm}$ in thickness compared with the wall using river sand and crushed gravel.

When the intensity of gamma ray was reduced to $1 / 1000$, the thickness of $47 \mathrm{~cm}$ was needed when using river sand as aggregate while the thickness of $41 \mathrm{~cm}$ was needed when the aggregate was replaced $100 \%$ with the rapidly-cooled steel slag, which was proven to reduce by about $6 \mathrm{~cm}$ in thickness compared with the wall using river sand crushed gravel as aggregate. When using fine and coarse aggregates together with rapidly-cooled steel slag, the thickness of $36.5 \mathrm{~cm}$ was needed, which was proven to reduce by about $10.5 \mathrm{~cm}$ in thickness compared with the wall using river sand and crushed gravel.

\subsubsection{Gamma ray of $\mathrm{Co}-10 \mathrm{MeV}$}

Figure 6 illustrates the results of an analysis by replacement rate and gamma transmissivity at $\mathrm{Co}-10 \mathrm{MeV}$ in a semi log plot.

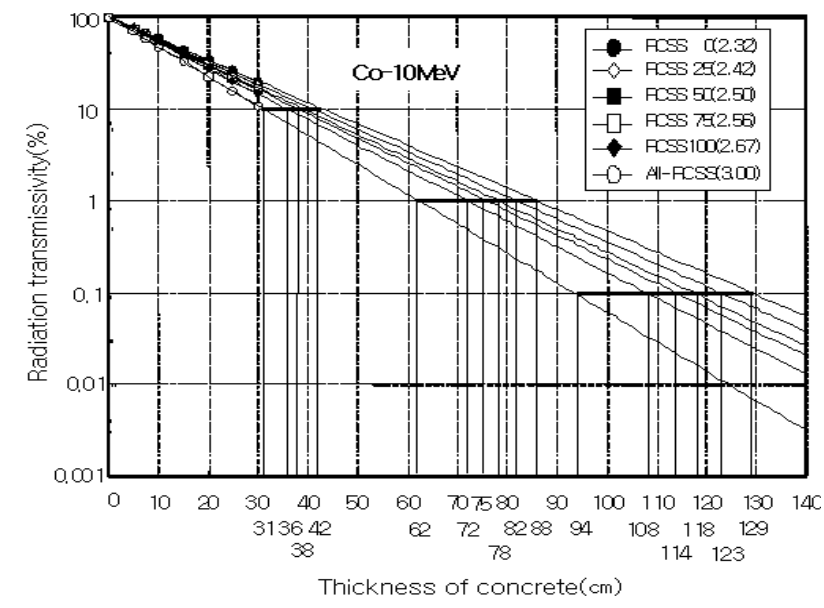

Figure 6. Correlation on the gamma transmissivity according to specimen thickness $(10 \mathrm{MeV})$

When the intensity of gamma ray of $\mathrm{Co}-10 \mathrm{MeV}$ was reduced by $1 / 10$, the thickness of $42 \mathrm{~cm}$ was needed when using river sand as aggregate while 
the thickness of $36 \mathrm{~cm}$ needed when the aggregate was replaced $100 \%$ with the rapidly-cooled steel slag, which was proven to reduce by about $6 \mathrm{~cm}$ in thickness. In addition, when using fine and coarse aggregates together with rapidly-cooled steel slag, the thickness of $31 \mathrm{~cm}$ was needed, which was proven to reduce by about $9 \mathrm{~cm}$ in thickness compared with the wall using river sand and crushed gravel as aggregate. When the intensity of gamma ray was reduced to $1 / 100$, the thickness of $88 \mathrm{~cm}$ was needed when using river sand as aggregate while the thickness of $75 \mathrm{~cm}$ was needed when the aggregate was replaced $100 \%$ with the rapidly-cooled steel slag, which was proven to reduce by about $13 \mathrm{~cm}$ in thickness compared with the wall using river sand crushed gravel as aggregate. When using fine and coarse aggregates together with rapidly-cooled steel slag, the thickness of $62 \mathrm{~cm}$ was needed, which was proven to reduce by about $26 \mathrm{~cm}$ in thickness compared with the wall using river sand and crushed gravel.

When the intensity of gamma ray was reduced to $1 / 1000$, the thickness of $129 \mathrm{~cm}$ was needed when using river sand as aggregate while the thickness of $108 \mathrm{~cm}$ was needed when the aggregate was replaced 100\% with the rapidly-cooled steel slag, which was proven to reduce by about $21 \mathrm{~cm}$ in thickness compared with the wall using river sand crushed gravel as aggregate. When using fine and coarse aggregates together with rapidly-cooled steel slag, the thickness of $94 \mathrm{~cm}$ was needed, which was proven to reduce by about $35 \mathrm{~cm}$ in thickness compared with the wall using river sand and crushed gravel.

\subsubsection{Neutron beam}

Figure 7 illustrates the results of an analysis of neutron beam by replacement rate and gamma transmissivity a semi log plot.

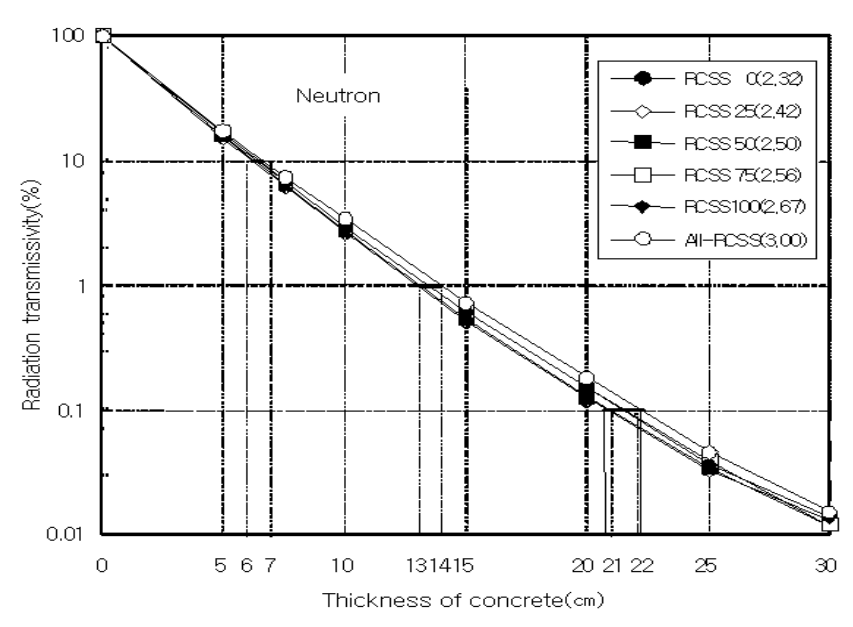

Figure 7 . Correlation on the gamma transmissivity according to specimen thickness(Neutron)

The gamma transmissity of neutron beam was decreased slightly according to the replacement ratio of rapidly-cooled steel slag, but there were no great differences. When the intensity of neutron beam was reduced by $1 / 10$, about $0.5 \mathrm{~cm}$ difference was found in thickness depending on replacement ratio of rapidly-cooled steel slag. When reduced by $1 / 100$ and $1 / 1000$, differences in thickness of about $1 \mathrm{~cm}$ and $1.2 \mathrm{~cm}$, respectively, were found. The transmissivity of general neutron beam was decreased as the specific gravity increased, but although the aggregate with high specific gravity was used in the test, there were no great differences found.

Through the test analysis, it was found that the higher the density, the lower the intensity of gamma ray, from which it is concluded that the density had an impact on gamma ray. In addition, it is believed that the increase range of density of concrete has a linear relationship with the decrease ratio of intensity of gamma ray.

\section{Conclusion}

The research findings of shielding concrete 
analysis depending on thickness and replacement ratio of rapidly-cooled steel slag can be summarized as follows:

1) Through the analysis of shielding performance, it was found that for the gamma ray, the higher the replacement ratio of rapidly-cooled steel slag, the better the shielding performance. For the neutron beam, the shielding performance was slightly deteriorated when rapidly-cooled steel slag was used as aggregate.

2) It was found that for the gamma ray, the higher the replacement ratio of rapidly-cooled steel slag, the lower the transmissivity, and when the rapidly-cooled steel slag is used as aggregate, the wall thickness is expected to be decreased. In addition, when fine and coarse aggregates are used with rapidly-cooled steel slag, the wall thickness will be decreased more than when only fine and coarse aggregates are used.

\section{Acknowledgement}

This study was supported by the Regional Cooperation Project of Ministry of Knowledge Economy(R0000621) and R\&D Center for Valuable Recycling(Global-Top Environmental Technology Development Program) funded by the Ministry of Environment.(Project No: 11-C21-ID)

\section{References}

1. Boo CY, Jang CI. A Study on the Radiation Shielding of Heavyweight Concrete using Metal Aggregate. Journal of Architectural Institute of Korea. 1998 June;14(4):361-8.

2. Han CG, Baeg YG, Ban HY, Kim EE. The Radiation Shield Properties of High Density Concrete Using Magnetite Aggregate. Journal of Architectural Institute of Korea. 1998
Dec;6(6):309-15.

3. Moon HY, Yoo JH, Chaen SH, Baeg EY. The Properties of Steel Slag Aggregate Treated with Aging Process in Concrete. Journal of Concrete Institute of Korea. 2001 Nov;1(1):105-9.

4. Tamura M. Study about Apply of Concrete Materials used industrial waste. Journal of Concrete Institute of Japan. 2000 Nov;11(1):41-71.

5. Moli NG. Composition of Concrete used Electric Arc Furnace Oxidizing slag aggregate. Journal of Concrete Institute of Japan 1994;16(1):319-24.

6. Kim JM, Cho SH, Oh SG, Kwak EG. Properties of Rapidly-Cooled Steel Slag by Atomizing Process. Journal of Concrete Institute of Korea. 2007 Oct;19(6):39-45.

7. Cho SH, Han GS, Park SE, Oh SG, Kwon GJ, Kim JM. Properties of Mortar Using Steel Slag Fine Aggregate. Journal of Concrete Institute of Korea. 2003 Nov;1(1):217-22.

8. Kim JM, Cho SH, Kwon GJ, Kim MH. An Experimental Study on the Engineering Properties of Radiation Shielding Concrete According to the Replacement Ratio of Rapid-Chilled Steel Slag Fine Aggregate. Journal of Architectural Institute of Korea. 2005 Oct;121(3):121-8.

9. Moli NG. Commercialization of Special Concrete used Electric Arc Furnace Oxidizing slag aggregate. Journal of Concrete Institute of Japan 1998;20(2):319-24.

10. Kim DS, Cho NJ. Calculation of Gamma streaming on the Cylinder used Monte-carlo method. Journal of Korea Nuclear Society. 1993;25(1):80-90. 